\title{
皖苏地区幔源物质的氧同位素组成 *
}

\author{
，支霞臣 (1) 李一良 ${ }^{(1)}$ 郑永飞(1) \\ (1)中国科学技术大学地球和空间科学系,合肥 230026; \\ (2)第三世界科学院中国科学技术大学地球科学和天文学高级研究中心, 合肥 230026)
}

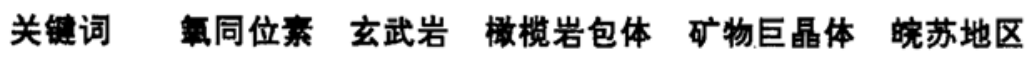

氧同位素组成对于了解岩石成因、地幔不均一性和壳-幔相互作用等具有重要意义. 国外 对幔源物质的 $\delta^{18} \mathrm{O}$ 作了大量测定, 揭示了地幔 $\delta^{18} \mathrm{O}$ 的不均一性, 玄武岩的高、低 $\delta^{18} \mathrm{O}$ 的地幔 源区, 以及 $\delta^{18} \mathrm{O}$ 和 $\mathrm{Nd}, \mathrm{Sr}, \mathrm{Pb}$ 同位素组成的协变性等 ${ }^{[1,2]}$. 国内研究报道甚少, 与 $\mathrm{Sr}, \mathrm{Nd}, \mathrm{Pb}$ 同位素和 REE 等痕量元素地球化学研究相比较, 存在明显差异. 本文报道皖苏地区新生代大 陆玄武岩、幔源橄榄岩包体、单斜辉石和歪长石巨晶捕虏体的 $\delta^{18} \mathrm{O}$, 并讨论其地球化学意义.

\section{1 样品和分析结果}

皖苏地区的玄武岩是我国东部新生代大陆玄武岩带的重要组成部分, 由六合-仪征和嘉 山-来安两区构成. 六合-仪征和女山的玄武岩碱性较强, 为霞石岩、碧玄岩和碱性橄榄玄武 岩, 富含橄榄岩、单斜辉石和歪长石巨晶捕虏体 ${ }^{[3]}$. 嘉山-来安的玄武岩碱性较弱, 为碱性橄榄 玄武岩、橄榄玄武岩和橄榄拉斑玄武岩, 不含幔源岩矿捕虏体 ${ }^{[4]}$.

本文分析了六合-仪征玄武岩样品 22 个, 嘉山-来安的 18 个. 女山的尖晶石二辉檄榄岩 包体样品 8 个,盘石山的 6 个. 女山的单斜辉石巨晶 6 个, 歪长石巨晶 1 个. 样品的 $\delta^{18} \mathrm{O}$ 用 常规的 $\mathrm{BrF}_{5}$ 法分析, 精度优于 $\pm 0.2 \%$, 结果以直方图表示 (图 1(a), (b)).
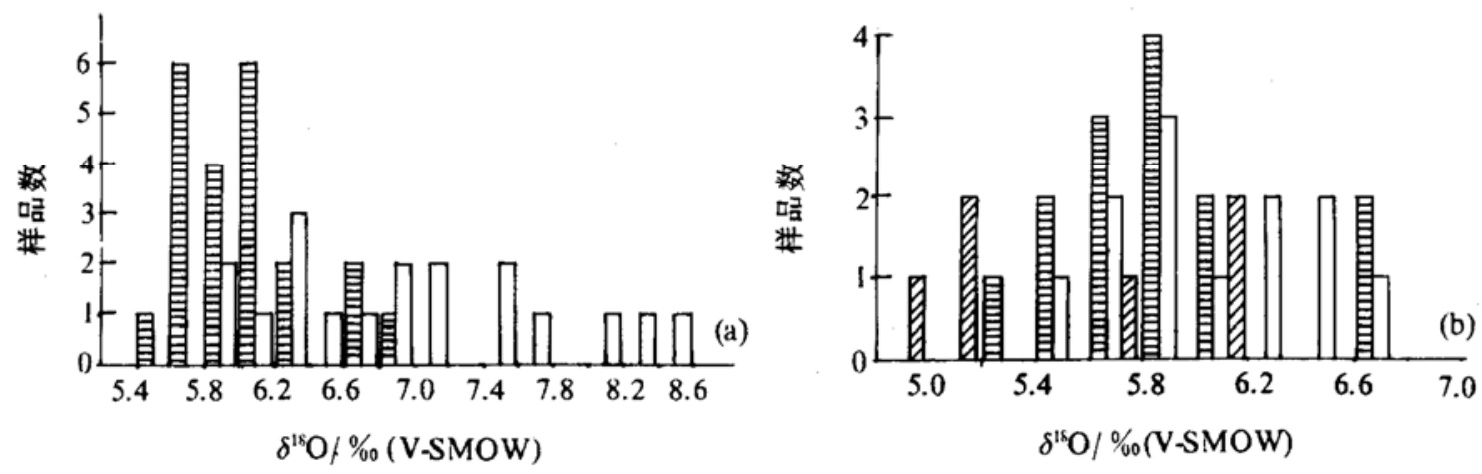

图 1 皖苏地区幔源物质氧同位素组成直方图

(a)玄武岩: 横线长条为六合-仪征区, 空白长条为嘉山-来安区; (b)檦榄岩和矿物巨晶捕虏体: 横线长条为檄㭠岩中的单 斜辉石, 空白长条为斜方辉石, 斜线长条为单斜辉石巨晶

1995-10-13 收稿, 1996-04-10 收修改稿

* 国家自然科学基金和中国科学院专项基金资助项目 
六合-仪征 22 个玄武岩的 $\delta^{18} \mathrm{O}=5.6 \sim 7.0(\%, \mathrm{~V}-\mathrm{SMOW}$, 下同), 均值为 $6.0 \pm 0.4(\sigma$, 下 同); 嘉山-来安 18 个玄武岩为 $6.0 \sim 8.5$, 均值为 $7.0 \pm 0.8 .14$ 个檄榄岩包体中的单斜辉石为 $5.3 \sim 6.7$, 均值为 $6.0 \pm 0.4 ; 12$ 个斜方辉石为 $5.6 \sim 6.7$, 均值为 $6.1 \pm 0.4 .2$ 个尖晶石为 5.6 和 6.5. 6 个单斜辉石巨晶为 $4.7 \sim 6.2$, 均值为 $5.5 \pm 0.6 .1$ 个歪长石巨晶为 6.5 .

\section{2 讨论}

\section{1 㯖山-来安玄武岩的高 $\delta^{18} \mathrm{O}$ 特征及其意义}

两区玄武岩的 $\delta^{18} \mathrm{O}$ 有明显差异. 六合-仪征的 $\delta^{18} \mathrm{O}$ 分布集中, 均值为 $6.0 \%$ (图 1), 比洋 中脊玄武岩 (MORB) 的均值 $5.7 \pm 0.2$ 稍大, 与大陆板内玄武岩 (CIB) 的均值 $6.1 \pm 0.7$ 相 同 ${ }^{[1]}$. 嘉山-来安的 $\delta^{18} \mathrm{O}$ 变异较大 (图 1), 高于 $\mathrm{CIB}$ 的均值, 低于意大利钾质玄武岩的均值 $8.5 \pm 1.3^{[1]}$, 因此表现为高 $\delta^{18} \mathrm{O}$ 特征. 两区玄武岩 $\delta^{18} \mathrm{O}$ 的不同反映了成因的差异.

两区玄武岩的主要成分和 $\mathrm{Sr}, \mathrm{Nd}$ 同位素组成有明显区别(图 2) ${ }^{[3-5]}$. 六合-仪征玄武岩 的 $\mathrm{Nd}$ 和 $\mathrm{Sr}$ 同位素组成比较均一, 具亏损地幔的特征 ${ }^{[5]}$, 相似于 PREMA 端元组分 ${ }^{[6]}$, 来源于 深部较均匀的地幔源区, 氧同位素特征支持这种观点. 嘉山-来安玄武岩的 $\mathrm{Nd}$ 和 $\mathrm{Sr}$ 同位素组

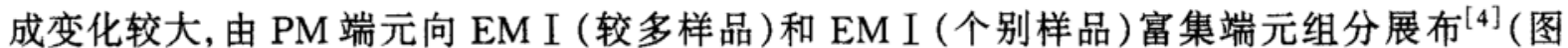
2). EM I 组分最近似于原始地幔组分或是稍经富集的原始地幔组分, 长期位于不受地幔对 流影响的核-幔边界处或大陆岩石圈地幔部分 ${ }^{[6]}$ 。嘉山-来安玄武岩的高 $\delta^{18} \mathrm{O}$ 特征表明其源 区不可能是未受扰动的原始地幔. 相反, 其源区具有开放性, 即由再循环的壳源物质的残余体 经活化作用,提供了高 $\delta^{18} \mathrm{O}$ 组分. 地幔源区的混合作用造成了玄武岩的高 $\delta^{18} \mathrm{O}$ 特征. 郯庐断裂东 侧嘉山-来安玄武岩揭示的岩石圈物质返回地幔的现象, 可能为探讨鄰庐断裂的性质提供新的启示.

\section{2 檄榄岩包体中两种辉石的羍同位素平衡分泾}

图 3 表示橄榄岩包体中两种辉石的氧同位素分馏. 9 个样品 $\left|\delta^{18} \mathrm{O}_{(\mathrm{Opx}-\mathrm{Cpx})}\right| \leqslant 0.5 \%, 3$ 个 稍有偏离. 9 个样品 $\delta^{18} \mathrm{O}_{\mathrm{Opx}} \geqslant \delta^{18} \mathrm{O}_{\mathrm{Cpx}}, 3$ 个相反. 总之, 皖苏地区䔩榄岩包体中两种辉石的

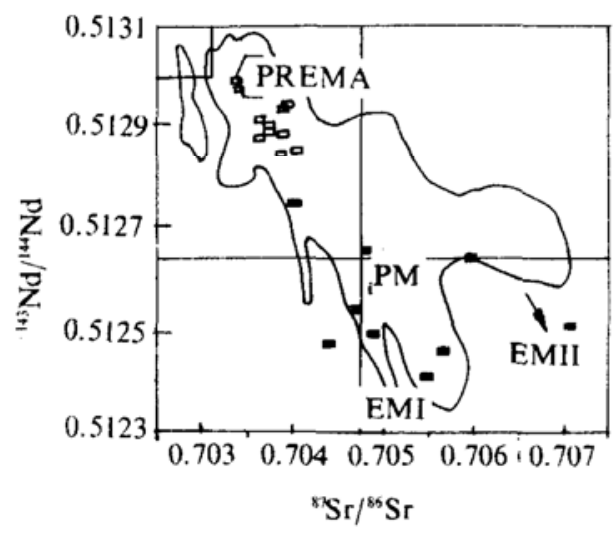

图 2 皖苏地区新生代玄武岩的 Nd-Sr 同位素特征 空心方块为六合-仪征玄武岩, 实心方块为嘉山-来安玄武岩

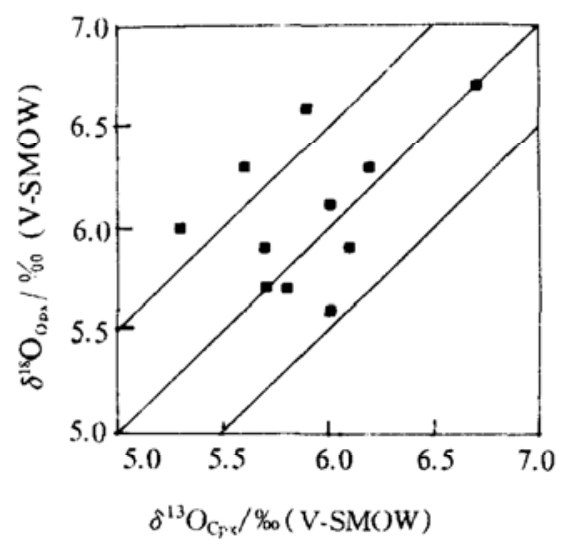

图 3 皖苏地区檄榄岩包体中两种辉石的氧 同位素分馏

1)支霞臣, 冯家麟. 汉诺坝玄武岩和幔源包体的氧同位索组成. 见: 第四届全国同位素地质年代学和地球化学学术讨 论会论文(摘要)汇编, 1989.160 161 
氧同位素分馏达到了平衡 ${ }^{[7,8]}$. 与世界上许多地区的相同 ${ }^{[2,7]}$, 也与我国汉诺坝的相同 ${ }^{1)}$. 该 区橄榄岩包体的 $\mathrm{Sr}$ 和 $\mathrm{Nd}$ 同位素组成表现为亏损地幔特征 ${ }^{[9]}$, 而部分幔源单斜辉石的微量元 素特征显示了隐性地幔交代作用的影响 ${ }^{[10]}$. 但是辉石的 $\delta^{18} \mathrm{O}$ 却没有明显反映.

\section{3 矿物巨晶捕虏体的莘同位案组成}

玄武岩中的矿物巨晶捕掳体通常认为是高温玄武岩熔体, 往往不是寄主玄武岩熔体, 在岩 石圈地幔或壳一幔边界处由结晶作用或伟晶作用产生的. 单斜辉石巨晶的 $\delta^{18} \mathrm{O}$ 均值 $5.5 \%$ 土 $0.6 \%$, 接近大陆溢流玄武岩 $(\mathrm{CFB})$ 的均值 $5.6 \% \pm 0.6 \%{ }^{[1]}$ 支持这种观点. 一个歪长石巨晶 的 $\delta^{18} \mathrm{O}$ 为 $6.5 \%$, 虽然稍高于单斜辉石, 但仍是玄武质熔体的结晶产物. 在 $T<1300^{\circ} \mathrm{C}$ 时, 歪长石和单斜辉石与玄武岩熔体的分馏系数有所不同, 前者大于 1 , 而后者小于 $1^{[8]}$.

\section{3 结论}

皖苏地区幔源物质的 $\delta^{18} \mathrm{O}$ 测定表明了该区地幔氧同位素组成的不均一性, 及其与放射成 因同位素 $\mathrm{Nd}, \mathrm{Sr}$ 组成的协变性. 六合-仪征玄武岩、女山和盘石山橄榄岩包体中的辉石和矿物 巨晶体的 $\delta^{18} \mathrm{O}$, 作为一级特征, 都为正常的地幔氧同位素组成. 但是嘉山-来安的玄武岩具有 高 $\delta^{18} \mathrm{O}$ 特征, 其 $\mathrm{Nd}$ 和 $\mathrm{Sr}$ 同位素组成呈现 $\mathrm{EM}$ 型富集地幔的特征, 再循环的壳源物质的残余 体提供相应的富集组分, 地幔混合作用造成了玄武岩的富集源区.

\section{参 考 文 献}

1 Harmon R S, Hoefs J. Oxygen isotopes heterogeneity of the mantle deduced from global $\delta^{18} \mathrm{O}$ systematics of basalts from different geotectonic settings. Contrib Mineral Petrol, 1995, 120:95 114

2 Kyser T K. Stable isotopes in the continental lithospheric mantle, In: Menzies M A ed. Continental Mantle. Oxford: Clarendon Press, 1990. 127 156

3 支霞臣. 六合-仪征第三纪大陆碱性玄武岩微量元亲地球化学. 岩石学报, 1990,6(2):30 42

4 支晸臣, 陈道公, 杨 晶. 皖东上第三系玄武岩的地球化学特征和成因. 地质学报, 1995,69:156 168

5 支霞臣, 陈道公, 张宗清等. 六合-仪征第三纪碱性玄武岩的钽-锶同位素组成. 岩石学报, 1994, 10:382 389

6 Zindler A, Hart S R. Chemical geodynamics. Ann Rev Earth Planet Sci, 1986, 14:493 571

7 Mattey D, Lowry D, Macpherson C. Oxygen isotope composition of mantle peridotite. Earth Planet Sci Lett, 1994, 128:213 $\sim 241$

8 Zheng Y F. Calculation of oxygen isotope fractionation in anhydrous silicate minerals. Geochim Cosmochim Acta, 1993, 57: $1078 \sim 1091$

9 陈道公, 支霞臣, 李㮏贤等. 江苏盘石山二辉㯙笕岩包体的 $\mathrm{Nd}, \mathrm{Sr}, \mathrm{Pb}$ 同位夷特征. 地球化学, 1994, (3):245 253

10 支霞臣, 李枇贤, 陈道公. 盘石山䐘源透辉石微量元素地球化学. 地质科学, 1995, 30:384 392 